\title{
Food technologies and developing countries: a processing method for making edible the highly toxic cassava roots
}

\author{
Milena Lambri, Maria Daria Fumi \\ Istituto di Enologia e Ingegneria Agro-Alimentare, Università Cattolica del Sacro Cuore, \\ Piacenza, Italy
}

\begin{abstract}
In addition to be a possible solution to the food crisis becoming a productive model to follow, the development of a process and/or a technique of food production in a developing country could create advantages from an industrial point of view due to the use of alternative raw materials, which have a potentially high competitiveness. In developing countries, agriculture is able to offer a variety of products making up the daily diet and provide products with potential that could make up for many nutritional deficiencies to which resident populations are subject. Food technology applications on cereals, tubers, roots, fruits, and by-products from related processes are reported at aiming to obtain finished and semi-finished foods and/or basic ingredients meeting the food safety criteria. In detail, this study aims to generate a processing method for the white bitter roots collected in a rural area of Burundi with a cyanogenic glycoside content $>400 \mathrm{mg}$ cyanide equivalent/kg dry weight. A standardised procedure consisting of peeling, grating, and oven drying at $60^{\circ} \mathrm{C}$, with or without fermentation with Saccharomyces cerevisiae, was successfully tested.
\end{abstract}

\section{Introduction}

Feeding the Planet. Energy for Life, the theme chosen for the Expo 2015 is emblematic to give an idea of the main problems dealing with

\footnotetext{
Correspondence: Milena Lambri, Istituto di Enologia e Ingegneria AgroAlimentare, Università Cattolica del Sacro Cuore, via Emilia Parmense 84, 29122 Piacenza, Italy.

Tel.: +39.0523.599178 - Fax: +39.0523 .599232 .

E-mail: milena.lambri@unicatt.it
}

Key words: cassava, developing countries, food safety, food security, fruits, nutrition, process development, roots, tubers.

Conference presentation: AISSA Conference, Piacenza, 2013. Represented society: Società Italiana di Scienze e Tecnologie Alimentari (SISTAL).

Received for publication: 26 December 2013.

Revision received: 6 March 2014.

Accepted for publication: 8 March 2014.

(C) Copyright M. Lambri and M.D. Fumi, 2014

Licensee PAGEPress, Italy

Italian Journal of Agronomy 2014; 9:573

doi:10.4081/ija.2014.573

This article is distributed under the terms of the Creative Commons Attribution Noncommercial License (by-nc 3.0) which permits any noncommercial use, distribution, and reproduction in any medium, provided the original author(s) and source are credited. in the next years. By 2050 the world's population will reach 9.1 billion, 34 percent higher than today. Nearly all of this population increase will occur in developing countries. In order to feed this larger, more urban and richer population, food production (net of food used for biofuels) must increase by 70 percent. Annual cereal production will need to rise to about 3 billion tons from 2.1 billion today and annual meat production will need to rise by over 200 million tons to reach 470 million tons (FA0, 2009). But increasing production is not sufficient to achieve food security, although it has improved as high income and agricultural growth has reduced the number of undernourished people from $21 \%$ in 1990 to $12 \%$ today (OECD-FAO, 2013).

The two major challenges to be address in order to contain the problems of food crisis and food security respectively are the reduction of food wastes in developed countries and the efforts to be done to rationally transform the agricultural resources in developing countries (FA0, 2011). Each year about 1.3 billion tons, i.e. one-third of all food produced for human consumption in the world is lost or wasted. Industrialized and developing countries dissipate roughly the same amount of food as wastes and losses respectively. Food loss refers to a decrease in mass (dry matter) or nutritional value (quality) of food that was originally intended for human consumption. These losses are mainly caused by inefficiencies in the food supply chains, such as poor infrastructure and logistics, lack of technology, insufficient skills, knowledge and management capacity of supply chain actors, and lack of access to markets. In addition, natural disasters play a role. Food waste refers to food appropriate for human consumption being discarded, whether or not after it is kept beyond its expiry date or left to spoil. Often this is because food has spoiled but it can be for other reasons such as oversupply due to markets, or individual consumer shopping/eating habits. Food wastage refers to any food lost by deterioration or waste. Thus, the term wastage encompasses both food loss and food waste. Obviously, this food wastage represents a missed opportunity to improve global food security and to mitigate environmental impacts generated by agriculture (FAO, 2011).

Agriculture and agribusiness together are projected to be a US\$ 1 trillion industry in Sub-Saharan Africa by 2030 (compared to US $\$ 313$ billion in 2010), and they should be at the top of the agenda for economic transformation and development. Successful agribusiness investments in turn stimulate agricultural growth through the provision of new markets and the development of a vibrant input supply sector (World Bank, 2013).

\section{Practical application of food technology in developing countries gaining food security: some examples of food process development}

Little is known about the potential agricultural resources that are available in developing countries, where about 2 billion of people suffer the so-called hidden undernutrition. This term refers to the undernutrition provoked by micronutrient deficiencies although in presence of enough macronutrients satisfying for energy needs (FA0, 2000). A better knowledge of the nutritional properties of the traditional crops 
in developing countries helps to realise food technology processes aimed at transforming, making safe and preserving the food/nutrition$\mathrm{a} /$ sensory value of the food product.

In sub-Saharan Africa traditional cereals such as uburo, a small and sweet sorghum, and elezine, commonly known as finger millet, are characterised by preservation properties and good resistance to hydric stress (Guiro et al., 2010). Elezine is used to make bread, soups, cakes, but is also employed in the production of beer, which is a source of nitrogen compounds and polyphenols (Fumi et al., 2009, 2011) for this population. The most common tubers are cassava and potatoes and finally the most important legumes are beans and peas (Guiro et al., 2010; Lambri et al., 2011c). Among tropical fruits (avocado, mango, papaya, banana, pineapple, passion fruit, etc.), papaya is an excellent source of vitamin A and C, it also contains thiamine, riboflavin, minerals, calcium, iron, potassium, magnesium and sodium (USDA, 2011).

A sustainable food process may reduce post-harvest losses in South East Asian Countries (Boselli, 2012) or may create rural development in Burundi giving rise to an avocado oil mill throughout an integrated approach (Lambri et al., 2010). On the other hand, the process development aimed at producing dehydrated crude papain from fresh papaya pulp with planning lab-scale, and pilot-scale trials (Lambri et al., 2014b) is an example of the production of high-value added ingredients which may be exploited in industrialized countries in order to get income for moving on the production in the developing country. In this regard, other application is the production of starch, maltodextrins and glucose syrup from cassava using the enzymatic hydrolysis steps (Lambri et al., 2011a, $2011 \mathrm{~b}, 2014 \mathrm{a})$. Other issue related to fruit processing is the recovery of wastes so reducing environmental pollution and fruit losses, and making the process more sustainable. An example in this framework regards the process of pineapple wastes into vinegar, which may be used as dressing, food preservative, and disinfectant (Roda et al., 2014). Finally the study aimed to obtain a baked product using ingredients found in Burundi (flour, cereals and legumes, papaya and avocado fruit, avocado oil), suggests that, in addition to sensory pleasantness, a nutritional composition can also be reached according to UN guidelines for the realization of biscuits for emergency food situations (Lambri et al., 2013b). Furthermore, the results obtained from a preliminary approach to fortify some flour, confirm the success of this technique in the integration of mineral components (Lambri et al., 2013c).

\section{Practical application of food technology in developing countries gaining food safety: a processing method for making edible the highly toxic cassava roots}

The cassava (Manihot esculenta Crantz) crop is extensively cultivated in the tropics, where approximately 800 million people rely on it as a staple food (FAO/FAD, 2000). The major factor limiting its food value is the presence of linamarin and lotaustralin, two cyanogenic glycosides (CNG) that liberate glucose and cyanohydrins upon hydrolysis by the endogenous enzyme linamarase. CNGs are distributed widely throughout the plant, with large amounts in the leaves and the root cortex and generally smaller amounts in the root parenchyma (Montagnac et al., 2009). The roots of different cultivars may be classified as low ( $<50 \mathrm{mg} / \mathrm{kg}$ ), medium $(50-100 \mathrm{mg} / \mathrm{kg}$ ) and high $\mathrm{CN}$ (>100 mg CN eq./kg) varieties (Nambisan, 2011). Moreover, several studies indicate that bitterness is related to the CNG content, and this affects the palatability of the roots and related flours (ChiwonaKarltun et al., 2004). Because the consumption of cassava products with high CNG levels may cause acute intoxication, aggravate goitre (Mlingi et al., 1992) and, in severe circumstances, induce paralytic diseases (Tylleskar et al., 1992) the Codex Alimentarius Commission of the Food and Drug Administration/World Health Organization (CCFO, 1981; FAO/WHO, 1991) set safe levels of cyanogens in cassa- va food products at $10 \mathrm{mg} / \mathrm{kg}$ dry weight (d.w.).

Processing has been recognised as the most efficient way of controlling cassava cyanogens in the short term, and a wide diversity of processing methods are used in cassava-consuming communities (Bradbury, 2006; Essers et al., 1996; Mlingi et al., 1995). Sun-drying cassava chips with or without prior grating/pounding removes $80 \%$ to 95-99\% of CNGs (Nambisan and Sundaresan, 1985). Oven-drying at $60^{\circ} \mathrm{C}$ with prior yeast fermentation reduced the cyanide levels by more than $90 \%$, generating safe cassava according to the FAO/WHO amendments (1991) if the initial cyanide level of roots did not exceed 200 $\mathrm{mg} / \mathrm{kg}$ d.w. (Lambri et al., 2013a). Particularly for varieties that are high in CNGs, the most popular and efficient processing method for their removal is fermentation (Lambri et al., 2013a; Nambisan, 2011). Lactic acid bacteria and yeasts have been identified as the predominant microorganisms involved in cassava fermentation (Oboh and Akindahunsi, 2003; Okafor et al., 1998; Oyewole, 2001). Examples of fermented foods include gari, fufu, lafun, casaba, and farina, in which CNG retention can occur with inadequate processing (Montagnac et al., 2009; Westby and Choo, 1994). Taking into account the retention of CNGs, the initial cyanide level of the root for the most efficient processing method (involving grating, fermentation, etc.) may not exceed 250 $\mathrm{mg} / \mathrm{kg}$ (Cardoso et al., 2005). Because the development of improved methods for the detoxification of cassava with high CNG content remains a challenging problem, this study aims to generate a processing method for the white bitter roots collected in a rural area of Burundi with a CNG content $>400 \mathrm{mg} \mathrm{CN}$ eq. $/ \mathrm{kg}$ d.w. A standardised procedure consisting of peeling, grating, and oven drying at $60^{\circ} \mathrm{C}$, with or without fermentation with selected cultures of Saccharomyces cerevisiae, was tested.

\section{Materials and methods}

\section{Cassava samples}

Cassava roots were collected directly from a rural market in Gitega, Burundi. Based on the taste properties related to their parenchyma cyanide content (Chiwona-Karltun et al., 2004), all the samples were bitter white cassava. The roots were peeled and cut with a knife. They were mixed together and grated into small sticks (10 mm length x 5 mm width $\mathrm{x} 1 \mathrm{~mm}$ thickness) with a Kenwood Chef Major Titanium KM020 equipped with a Vegetable Processor AT340 supplied by De Longhi Appliances s.r.l. (Treviso, Italy).

\section{Drying tests}

The drying tests involved drying grated cassava samples in an oven for 8,24 or $72 \mathrm{~h}$ at a unique temperature of $60^{\circ} \mathrm{C}$, which was reported to be highly effective in a recent study (Lambri et al., 2013a). An electric convection oven with a humidifier (Mod. 4XGN1/1 supplied by Virtus s.r.l., Pavia, Italy) and $1 \mathrm{~m} / \mathrm{s}$ forced airflow was used. Thin layers of grated cassava samples were oven dried with and without previous triplicate fermentation processes with selected cultures.

\section{Microbial samples and fermentation tests}

The microbial samples were composed of of active dry $S$. cerevisiae yeasts for oenological features (AEB, Brescia, Italy) grown in Malt Extract Broth. The solution used for yeast nutrition was Yeast Nitrogen Base (OXOID, Hampshire, UK). Fermentation tests were performed at a ratio of $1000 \mathrm{~g}$ cassava $/ 1500 \mathrm{~mL}$ of water in open containers under the same conditions applied by Lambri et al. (2013a). A fermentation time of $48 \mathrm{~h}$ and a temperature of $30 \pm 2^{\circ} \mathrm{C}$ were applied. For each trial, an uninoculated grated cassava sample was also maintained. 


\section{Proximate analysis and cyanide determination of cassava samples}

Moisture, ash, crude fibre, and the protein content of the cassava root samples were determined (AOAC, 1995). The tannin content was evaluated (Singleton et al., 1998), and the CNG content was indirectly measured (Bradbury et al., 1999) using a picrate paper kit, linamarase (50 EU) and linamarin (BDH, Milan, Italy). The method involves the immobilisation of linamarase in a small filter paper disc also loaded with phosphate buffer at $\mathrm{pH} 8$. The disc is placed in a small vial, and 100 $\mathrm{mg}$ of cassava is added with $0.5 \mathrm{~mL}$ water. A strip of yellow picrate paper, previously prepared, is inserted, and the vial is capped. After 24 $\mathrm{h}$ at $25-35^{\circ} \mathrm{C}$, the picrate paper was separated from the plastic strip, and the colour was eluted from the filter paper in $5.0 \mathrm{~mL}$ water for approximately $30 \mathrm{~min}$. The absorbance of the solution is measured at $510 \mathrm{~nm}$ against a blank that contained a yellow solution produced from a picrate paper not exposed to HCN. The toxicity of the untreated cassava roots and samples after peeling-grating, fermentation, and drying is expressed as $\mathrm{mg} \mathrm{CN}$ eq./kg d.w.

\section{Statistical analysis}

All the data were subjected to analysis of variance (ANOVA) via Microsoft Excel 2010 for Windows7. Mean comparisons were performed using Student's t-test and the post-hoc comparison Tukey's test with the significant level established at $\mathrm{P}<0.05$. The statistics were prepared using IBM SPSS Statistics 20 (IBM Corporation, New York, NY, USA).

\section{Results and discussion}

\section{Effect of peeling and grating on cyanide abatement}

Cassava roots were characterised by levels of moisture $(47.5 \pm 2.1 \%$ w/w), ash $(1.77 \pm 0.60 \%$ w/w d.w.), fibre $(3.54 \pm 0.68 \%$ w/w d.w.), tannins $(0.34 \pm 0.03 \mathrm{mg} / 100 \mathrm{~g}$ d.w. $)$, and proteins $(3.36 \pm 0.77 \% \mathrm{w} / \mathrm{w}$ d.w. $)$, confirming the proximate analysis previously reported (Lambri et al., 2013a; Charles et al., 2005; Sarkiyayi and Agar, 2010). The initial toxicity level of the roots was $593 \pm 89 \mathrm{mg} \mathrm{CN}$ eq. $/ \mathrm{kg}$ d.w., and the level detected after peeling and grating was $170 \pm 48 \mathrm{mg} \mathrm{CN}$ eq. $/ \mathrm{kg}$ d.w.

The attempt to correlate the cyanide reduction produced by peeling and grating as a function of the cyanide content in the unpeeled whole roots is reported in Figure 1. For the investigated bitter white cassava roots, the maximum degree of cyanide abatement $(75.2 \pm 7.4 \%)$ was observed for samples with cyanide content between 500 and $667 \mathrm{mg} \mathrm{CN}$ eq./kg d.w. For the highest (700 and $732 \mathrm{mg} \mathrm{CN} \mathrm{eq./kg} \mathrm{d.w.)} \mathrm{and} \mathrm{the} \mathrm{low-}$ est (442 mg CN eq./kg d.w.) initial cyanide values, the reductions produced by peeling and grating were significantly lower $(62.2 \pm 6.3 \%)$.

The operations of peeling and grating were the first substantial step of the process to lower cassava toxicity $(-71.3 \pm 6.9 \%$ of initial value) because CNGs are distributed in large amounts in the skin (Montagnac et al., 2009). Cutting and grating enhances intimate contact between linamarin and the hydrolysing enzyme linamarase, which promotes rapid breakdown of linamarin to hydrogen cyanide gas that escapes into the air in the finely divided wet parenchyma (Cardoso et al., 2005; Montagnac et al., 2009). Moreover, grating provides a higher surface area for both drying and fermentation and allows retting to be completed more quickly than when whole roots are used (Mlingi et al., 1992; Sakala et al., 2007). It is a valuable method for further investigation, especially in eastern and southern Africa, where attempts to introduce this method failed because of the cost and availability of the processors (Cardoso et al., 2005; Nebiyu and Getachew, 2011).

\section{Drying tests with and without fermentation}

Figure 2 summarises the cyanide levels measured after drying the grated cassava at $60^{\circ} \mathrm{C}$ for three different lengths of time and shows that very high reductions (close to 95\%) of the initial cyanide contents occurred even with short $(8 \mathrm{~h})$ drying periods. The detoxification was higher than that reported by Iwuoha et al. (1997), who observed a total cyanide reduction of $81.5 \%$ with oven drying at $50^{\circ} \mathrm{C}$ for $<24 \mathrm{~h}$. Despite the promising results (Figure 2) already observed in a recent study (Lambri et al., 2013a), the selected temperature of $60^{\circ} \mathrm{C}$ is near the critical limit for cyanide retention because linamarase activity is inhibited at temperatures above $55^{\circ} \mathrm{C}$ (Nambisan, 2011). The increase in drying temperature $\left(50-80^{\circ} \mathrm{C}\right)$ has long been known to be accompanied by an accumulation of linamarin in dried cassava (Iwuoha et al., 1997; Nambisan and Sundaresan,

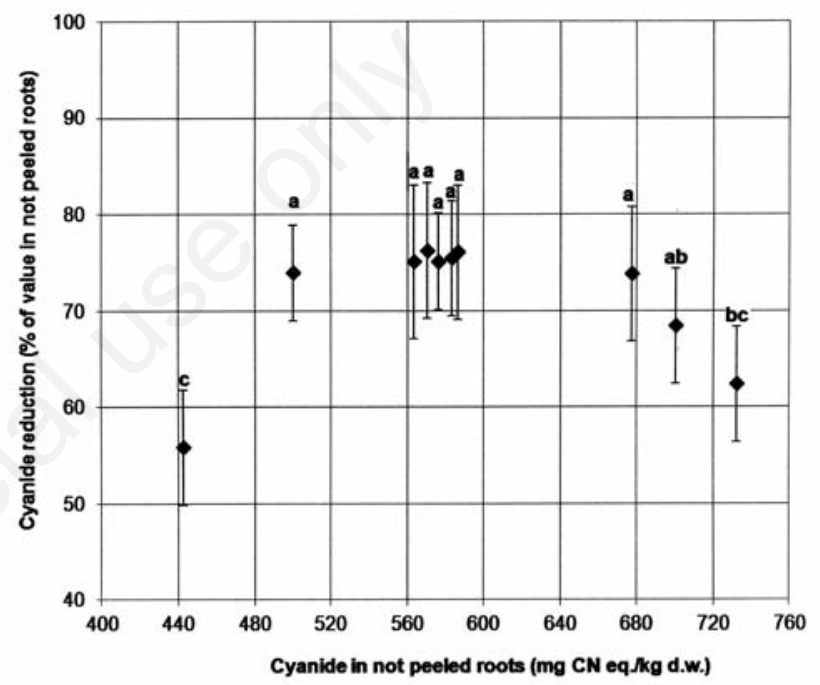

Figure 1. Cyanide reduction produced by peeling and grating $v$ the initial cyanide content in unpeeled cassava roots. Each point represents the mean \pm standard deviation $(\mathrm{N}=6)$. Different letters indicate significantly different values according to Tukey's posthoc comparison test $(\mathrm{P}<0.05)$.

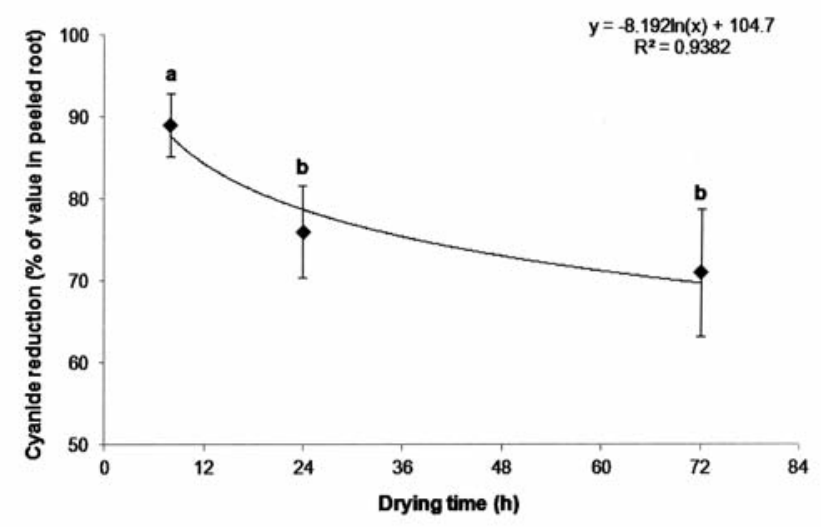

Figure 2. Cyanide reduction in peeled cassava roots produced after 8,24 and $72 \mathrm{~h}$ of oven drying at $60^{\circ} \mathrm{C}$. Each point represents the mean \pm standard deviation $(\mathrm{N}=6)$. Different letters indicate significantly different values according to Tukey's post-hoc comparison test $(\mathrm{P}<0.05)$. 
1985). In thin cassava pieces, because the surface-to-volume ratio is great, the drying rate is high (Essers et al., 1996). In this study, a low forced airflow $(1 \mathrm{~m} / \mathrm{s})$ was applied, allowing substantial detoxification (Figure 2). This is primarily due to a reduced surface pre-drying phenomenon, with a longer contact period between the glucosidase and the glucoside in aqueous medium (Essers et al., 1996). As a consequence, oven drying with an extended time span where the enzymesubstrate interaction is enhanced by moisture retention represents a potential method to increase the effectiveness of CNG removal.

The CNG abatement was highest in the first $8 \mathrm{~h}$ of the oven-drying process and decreased slightly over the following hours in a logarithmic trend (Figure 2), showing a similar decrease in the linamarin levels over time as in the work of Essers et al. (1996). This pattern may be explained here as these authors explained CNG reduction during sun drying. The enzymatic breakdown of a substrate in solution is either a first or higher order reaction, resulting in a negative exponential curve of the CNG level in grated cassava. A higher initial substrate level therefore logically results in a steeper decline than the lower level present after some time (Figure 2). After applying the sequential process steps of peeling-grating and $8 \mathrm{~h}$-oven-drying at $60^{\circ} \mathrm{C}$ to another aliquot of the white bitter root sample with $581 \pm 28 \mathrm{mg} \mathrm{CN}$ eq $/ \mathrm{kg}$ d.w., levels of $135 \pm 18 \mathrm{mg} \mathrm{CN}$ eq./kg d.w. in peeled grated cassava and $40 \pm 11 \mathrm{mg} \mathrm{CN}$ eq./kg d.w. after oven-drying were detected. Although consistent with other reports (Iwuoha et al., 1997), the peeling-grating-oven-drying sequence was not enough to ensuring the safety of the tested bitter white cassava roots according to the FAO/WHO guidelines (1991). As a consequence, selected cultures of $S$. cerevisiae used in a previous study (Lambri et al., 2013a) were applied at $30 \pm 2{ }^{\circ} \mathrm{C}$ for 48 -h fermentation of grated cassava before the oven drying step.

The fermentation promoted a significant CNG reduction. While the cyanide content of the uninoculated grated cassava was $169 \pm 12 \mathrm{mg} \mathrm{CN}$ eq./kg d.w., the inoculation of $S$. cerevisiae caused the cyanide content in the inoculated grated cassava to drop by $35 \%$ to $109 \pm 9 \mathrm{mg} \mathrm{CN}$ eq. $/ \mathrm{kg}$ d.w. Although natural flora has the ability to hydrolyse linamarin, these data confirmed the results of other studies regarding the fermentation of cassava roots soaked in water, in which microbial growth was shown to be essential for the efficient elimination of cyanogens (Okafor et al., 1998; Westby and Choo, 1994). Moreover, our results highlighted the efficiency of the yeast $S$. cerevisiae in removing CNGs (Lambri et al., 2013a; Oboh and Akindahunsi, 2003), which may be favoured by the increased acidity of the medium (Oyewole, 2001) over the $48 \mathrm{~h}$ of fer-

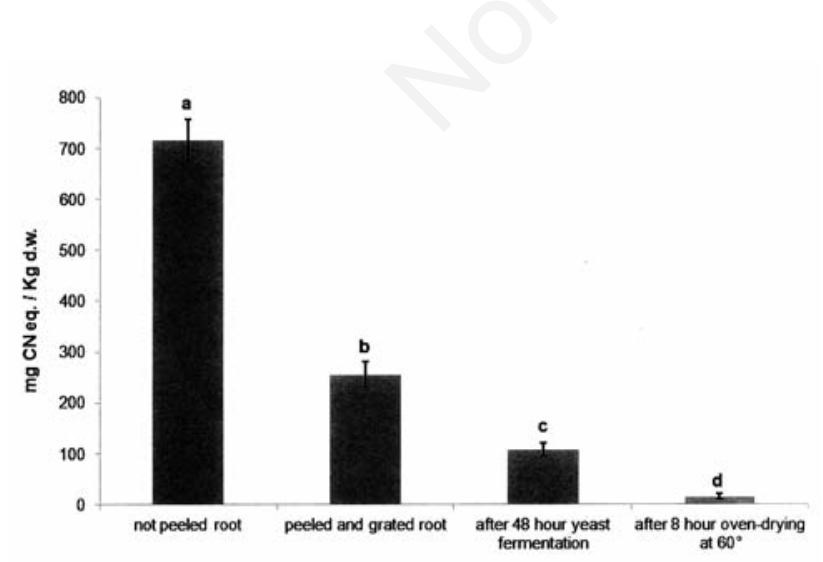

Figure 3. Cyanide content in unpeeled cassava roots, after peeling and grating, after 48-h fermentation with Saccharomyces cerevisiae, and after $8 \mathrm{~h}$ of oven drying at $60^{\circ} \mathrm{C}$. Each bar represents the mean \pm standard deviation $(\mathrm{N}=6)$. Different letters on top of the bar indicate significantly different values according to Tukey's post-hoc comparison test $(P<0.05)$. mentation. The addition of this yeast has been proven to produce a marked decrease in the level of hydrocyanic acid and other toxicants (Antai and Nkwelang, 1998) and is also a tool for enriching fermented cassava mash with crude proteins (Antai, 1990).

Finally, the sequential application of all the steps (peeling, grating, $48 \mathrm{~h}$ fermentation with $S$. cerevisiae, $60^{\circ} \mathrm{C}$ oven drying) to duplicate cassava sample aliquots with $716 \pm 42 \mathrm{mg} \mathrm{CN}$ eq. $/ \mathrm{kg}$ d.w. in unpeeled roots enabled the reduction of the cyanide level to a final value of $15 \pm 5$ $\mathrm{mg} \mathrm{CN}$ eq./kg d.w., i.e., a 48 -fold reduction (Figure 3), well within the safe CNG levels set by FAO/WHO (1991). The effectiveness of this processing method should be further tested by varying cassava root samples and processing times because the process sequence is often timedependent (Agbor-Egbe and Mbome, 2006).

\section{Conclusions}

The urgent shortage of raw materials, food and natural resources, makes clear the need to find alternative resources in order to make up for the global food requirements and achieve a balance between food demand and supply both in developed and in developing countries. The search for new resources should match the three issues of sustainability: economic, environmental and social. Raising the necessary resources at the global level and the promotion of economic and social development of peoples in developing countries is the dual aim to be got. The development of a process and/or a technique of food production in a developing country, in addition to be a possible solution to the food crisis becoming a productive model to follow, have to create advantages from an industrial point of view. Alternative raw materials, which have a potentially high competitiveness may be exploited and used by the Western food industry. As like as food security, the food safety of local crops is fundamental for producing both traditional foods and ingredients. In this framework devoted process development aimed at maximum reduction of the initial levels of toxic molecules in order to meet the FAO/WHO requirements and ensuring the safety of final products are needed.

\section{References}

Agbor-Egbe T, Mbome IL, 2006. The effects of processing techniques in reducing cyanogen levels during the production of some Cameroonian cassava foods. J. Food Compos. Anal. 19:354-63.

Antai SP, 1990. Enrichment of nutrient quality of cassava (Manihot esculenta Crantz) with microbial proteins. Plant Foods Hum. Nutr. 40:289-96.

Antai SP, Nkwelang G, 1998. Reduction of some toxicants in Icacina mannii by fermentation with Saccharomyces cerevisiae. Plant Foods Hum. Nutr. 53:103-11.

AOAC, 1995. Official methods of analysis, 16th ed. Association of Official Analytical Chemists, Washington, DC, USA.

Bradbury JH, 2006. Simple wetting method to reduce cyanogens content of cassava flour. J. Food Compos. Anal. 19:388-93.

Bradbury MG, Egan SV, Bradbury JH, 1999. Picrate paper kits for determination of total cyanogens in cassava roots and all forms of cyanogens in cassava products. J. Sci. Food Agric. 79:593-01.

Boselli E, 2012. Post harvest losses in fruits and vegetables in South East Asian Countries; the cases of Cambodia, Indonesia, Laos, Malaysia, Myanmar, Philippines, Thailand, Vietnam and Bangladesh, Ghana, India, Sri Lanka. Results of the workshop "Post-harvest, quality and food safety of tropical fruit production in South East Asian countries" organised by UNIDO-ICS, 30 April-4 May 2012, Bangkok, Thailand. 
Cardoso AP, Mirione E, Ernesto M, Massaza F, Cliff J, Haque MR, Bradbury JH, 2005. Processing of cassava roots to remove cyanogens. J. Food Compos. Anal. 18:451-60.

Charles AL, Sriroth K, Huang T, 2005. Proximate composition, mineral contents, hydrogen cyanide and phytic acid of 5 cassava genotypes. Food Chem. 92:615-20.

Chiwona-Karltun L, Brimer L, Saka JDK, Mhone AR, Mkumbira J, Johansson L, Bokanga M, Rosling H, 2004. Bitter taste in cassava roots correlates with cyanogenic glucoside levels. J. Sci. Food Agric. 84:581-90.

CCFO (Codex Committee on Fats and Oils), 1981. CODEX STAN 19-1981. Codex standard for edible fats and oils not covered by individual standards. Codex Alimentarius Commission of the Food and Drug Administration/World Health Organization, Rome, Italy. Available from: http:/www.codexalimentarius.org/standards/list-of-standards /en/?provide=standards\&orderField=fullReference \&sort=asc\&num= CODEX

Essers AJA, Van der Grift RM, Voragen AGJ, 1996. Cyanogen removal from cassava roots during sun-drying. Food Chem. 55:319-25.

FAO, 2000. The state of food insecurity in the world. Food and Drug Administration, Rome, Italy.

FA0, 2009. Global agriculture towards 2050. How to feed the world. Food and Drug Administration, Rome, Italy.

FAO, 2011. Global food losses and food waste. Study conducted for the International Congress "SAVE FOOD! at Interpack2011", Düsseldorf, Germany.

FAO/FAD, 2000. The World cassava economy: facts, trends and outlooks. Food and Agriculture Organization and International Fund for Agricultural Development, Rome, Italy.

FAO/WHO, 1991. Pesticide residues in food. Part I - Residues. Joint FAO/WHO Meeting on Pesticide Residues. FAO Plant Production and Protection Paper 113/1. Food and Drug Administration, Rome, Italy.

Fumi MD, Galli R, Lambri M, Donadini G, De Faveri DM, 2011. Effect of fullscale brewing process on polyphenols in Italian all-malt and maize adjunct lager beers. J. Food Compos. Anal. 24:568-73.

Fumi MD, Galli R, Lambri M, Donadini G, De Faveri DM, 2009. Impact of full-scale brewing processes on lager beer nitrogen compounds. Eur. Food Res. Technol. 230:209-16.

Guiro AT, Dossou-Idohou N, Wade S, 2010. The challenges of local foods for overcoming rural poverty and malnutrition in Western Africa. Int. Sci. Symp. on Biodiversity and Sustainable Diets United Against Hunger. Food and Drug Administration, Rome, Italy.

Iwuoha CI, Banigo EOI, Okwelum FC, 1997. Cyanide content and sensory quality of Cassava (Manihot esculenta Crantz) root tuber flour as affected by processing. Food Chem. 58:285-8.

Lambri M, Dordoni R, Roda A, De Faveri, 2014a. Process development for maltodextrins and glucose syrup from cassava. Chemical Engine. Trans. 38:469-74.

Lambri M, Fumi MD, Roda A, De Faveri DM, 2013a. Improved processing methods to reduce the total cyanide content of cassava roots from Burundi. Afr. J. Biotechnol. 12:2685-91.

Lambri M, Mautone D, Luraschi OA, Nitunga P, Bayran T, De Faveri DM, 2010. Realizzazione di una produzione di olio di avocado in Burundi (olio per la vita) nel rispetto dei requisiti di qualità e sicurezza alimentare tramite un approccio integrato. pp 99-102 in Proc. VIII Convegno AISSA, 24-26 novembre 2010, Udine, Italy.

Lambri M, Razzetti V, De Faveri DM, 2011a. Maltodestrine e sciroppi di glucosio da materie prime alternative. Macchine Alimentari. April:38-42.

Lambri M, Riggio G, Dordoni R, De Faveri DM, 2013b. Prodotti da forno con ingredienti reperibili in Paesi in via di sviluppo. Ingredienti Alimentari. XII:6-13.

Lambri M, Roda A, Dordoni R, Fumi MD, De Faveri DM, 2014b. Mild process for dehydrated food-grade crude papain powder from papaya fresh pulp: lab-scale and pilot plant experiments. Chemical Engine. Trans. 38:7-12.

Lambri M, Roda A, De Faveri DM, 2011b. Cassava, fonte alternativa di amidi. Macchine Alimentari. September:22-4.

Lambri M, Roda A, Riggio G, 2013c. Fortificazione degli alimenti. Una risposta alla malnutrizione. Macchine Alimentari. March:52-5.

Lambri M, Riggio G, De Faveri DM, 2011c. Opportunità globale. Materie prime alternative da Paesi in via di sviluppo. Macchine Alimentari. October:28-32.

Mlingi NLV, Bainbridge ZA, Poultefl NH, Rosling H, 1995. Critical stages in cyanogen removal during cassava processing in southern Tanzania. Food Chem. 53:29-3.

Mlingi NLV, Poulter NH, Rosling H, 1992. An outbreak of acute intoxication from insufficiently processed cassava in Tanzania. Nutr. Res. 12:677-87.

Montagnac JA, Davis CR, Tanumihardjo SA, 2009. Processing techniques to reduce toxicity and antinutrients of cassava for use as a staple food. Compr. Rev. Food Sci. F. 8:17-27.

Nambisan B, 2011. Strategies for elimination of cyanogens from cassava for reducing toxicity and improving food safety. Food Chem. Toxicol. 49:690-93.

Nambisan B, Sundaresan S, 1985. Effect of processing on the cyanoglucoside content of cassava. J. Sci. Food Agric. 36:1197-03.

Nebiyu A, Getachew E, 2011. Soaking and drying of cassava roots reducedcyanogenic potential of three cassava varieties at Jimma, Southwest Ethiopia. Afr. J. Biotechnol. 10:13465-69.

Oboh G, Akindahunsi AA, 2003. Biochemical changes in cassava products (flour and gari) subjected to Saccharomyces cerevisiae solid media fermentation. Food Chem. 82:599-02.

OECD/FA0, 2013. Agricultural Outlook 2013-2022. Available from: http:/www.oecd.org/site/oecd-faoagriculturaloutlook/summary-2013EN.pdf

Okafor N, Umeh C, Ibenegbu C, Obizoba I, Nnam N, 1998. Improvement of gari quality by the inoculation of microorganisms into cassava mash. Int. J. Food Microbiol. 40:43-9.

Oyewole OB, 2001. Characteristics and significance of yeasts' involvement in cassava fermentation for fufu production. Int. J. Food Microbiol. 65:213-8.

Roda A, De Faveri DM, Dordoni R, Lambri M, 2014. Vinegar production from pineapple wastes - Preliminary saccaharification trials. Chemical Engine. Trans. 37:607-12.

Sakala N, Hikeezi D, Shindano J, Chitundu K, Nyirenda D, Chitundu M, 2007. Evaluation of cassava rural processing techniques for hydrogen cyanide reduction. pp 228-31 in Proc. Atelier "Potentialitiés à la transformation du manioc en Afrique de l'Ouest”, 4-7 June, Abidjan, Ivory Coast.

Sarkiyayi S, Agar TM, 2010. Comparative analysis on the nutritional and anti-nutritional contents of the sweet and bitter cassava varieties. Adv. J. Food Sci. Technol. 2:328-34.

Singleton VL, Orthofer R, Lamuela-Raventós RM, 1998. Analysis of total phenols and other oxidation substrates and antioxidants by means of Folin-Ciocalteu reagent. Method Enzymol. 299:152-78.

Tylleskar T, Banea M, Bikangi N, Cooke RD, Poulter NH, Rosling H, 1992. Cassava cyanogens and konzo, an upper motoneuron disease found in Africa. Lancet. 339:208-11.

USDA, 2011. USDA National Nutrient Database for Standard Reference. Available from: http//ndb.nal.usda.gov/

Westby A, Choo BK, 1994. Cyanogen reduction during the lactic fermentation of cassava. Acta Hortic. 375:209-15.

World Bank, 2013. Growing Africa: unlocking the potential of agribusiness. Available from: http://siteresources.worldbank.org/INTAFRICA/ Resources/africa-agribusiness-report-2013.pdf 